\title{
Scar Endometriosis in a 30 Year Old Lady - A Cyto Histo Correlation
}

\author{
S. Srikanth ${ }^{1}$, N. Sreemani Kumari ${ }^{2 *}$, M. Jyothi ${ }^{3}$, Y. Sravanthi ${ }^{4}$
}

${ }^{1}$ Professor, Department of Pathology, Malla Reddy Institute of Medical Sciences, Suraram, Hyderabad, Telangana, India

${ }^{2}$ Professor \& Head, Department of Pathology, Malla Reddy Institute of Medical Sciences, Suraram, Hyderabad, Telangana, India

${ }^{3}$ Associate Professor, Department of Pathology, Malla Reddy Institute of Medical Sciences, Suraram, Hyderabad, Telangana, India

${ }^{4}$ Assistant Professor, Department of Pathology, Malla Reddy Institute of Medical Sciences, Suraram, Hyderabad, Telangana, India

DOI: $10.36347 /$ sjmcr.2021.v09i01.017

| Received: 08.01.2021 | Accepted: 19.01.2021 | Published: 23.01.2021

*Corresponding author: Dr. N. Sreemani Kumari

\section{Abstract}

Endometriosis is defined as the presence of a functioning endometrium outside the uterus. Abdominal wall endometriosis is a rare entity. Most of the abdominal wall endometriosis occurs in or around surgical scars following caesarean section or hysterectomy. Scar endometriosis is a rare disease, and is difficult to diagnose. The symptoms are nonspecific, typically involving abdominal wall pain at the incision site at the time of menstruation. It commonly follows obstetrical and gynecological surgeries.

Keywords: FNAC, scar endometriosis, abdominal wall.

Copyright $\odot 2021$ The Author(s): This is an open-access article distributed under the terms of the Creative Commons Attribution 4.0 International License (CC BY-NC 4.0) which permits unrestricted use, distribution, and reproduction in any medium for non-commercial use provided the original author and source are credited.

\section{INTRODUCTION}

Endometriosis is defined by the presence and growth of ectopic functional endometrial tissue outside the uterus. Scar endometriosis has been described following obstetrical and gynecological surgery. It is a rare condition, though probably on the rise, due to the considerable increase of cesarean sections performed worldwide. Its physiopathology is complex; its symptomatology is rich and diverse but thorough clinical examination along with ultrasound imaging and potentially pretherapeutic cytologic evaluation are usually efficient in diagnosing the condition.

It is a common gynecological condition that affects up to $22 \%$ of all women, $8-15 \%$ of women of reproductive age and $6 \%$ of premenopausal women [1, 2]. Most of the reported cases occurred in gynecologically induced abdominal or pelvic scars, including hysterectomy, episiotomy, caesarean section and laparoscopy $[3,4]$. It is extremely rare in a surgical scar, appearing in $0.1 \%$ of women who have undergone caesarean section. Its clinical diagnosis is confused with suture granuloma, hematoma, abscess, sarcoma, desmoid tumor and metastatic malignancy. We report a case of scar endometriosis in a woman who underwent caesarean.

\section{Case Report}

A 30 years female presented with lower abdominal pain since six months. Pain was on and off and increased during menstruation. Patient had a history of cesarean section three years back. On palpation, tiny nodule, measuring about $2 \times 2 \mathrm{~cm}$, was found just adjacent to cesarean section scar. Clinically and radiologically diagnosis of Desmoid tumour was made. Fine Needle Aspiration Cytology (FNAC) was done and it was diagnosed as Scar Endometriosis. Cytologically the cells showing high cellularity of glandular and stromal cells arranged in sheets, tight clusters having round to oval nuclei with uniform chromatin against eosinophilic background (Figure-1).

Patient was operated and the specimen was sent for histopathological examination. Grossly we received 2 skin covered soft tissue masses, each measuring around $3 \times 2.5 \mathrm{cms}$. Cut section showing grey white to grey yellow areas (Figure-2). Sections were given and microscopically it was showing skin covered by stratified squamous epithelium, sub epithelially showing fibrofatty and fibro collagenous tissue with many Endometrial glands and stromal elements along with skeletal muscle tissue and neural tissue and it was diagnosed as scar endometriosis on histopathologically (Figure-3). 


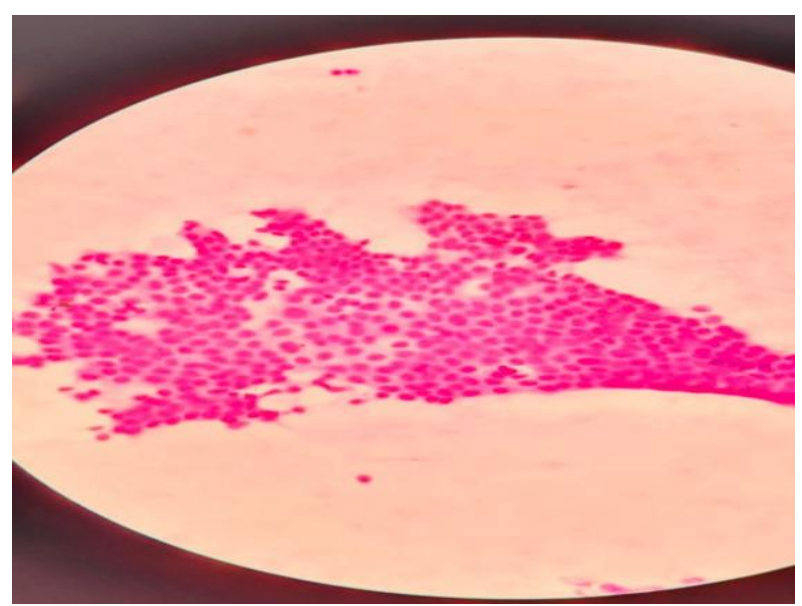

Fig-1: Cytology smears showing high cellularity of glandular and stromal cells arranged in sheets, tight clusters having round to oval nuclei with uniform chromatin against eosinophilic background [H\&E,x40]

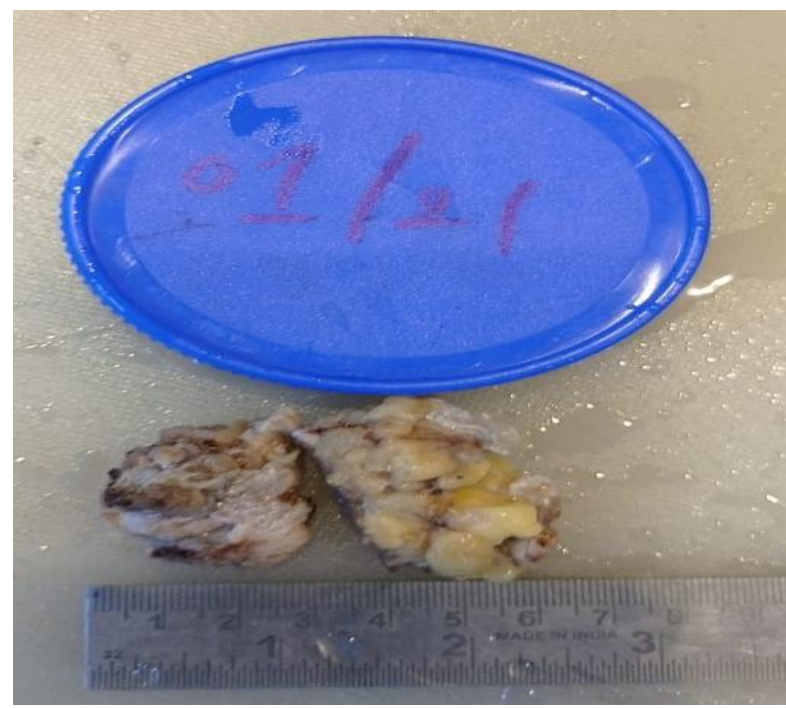

Fig-2: Gross showing skin covered soft tissue mass, grey white to grey yellow on cut section

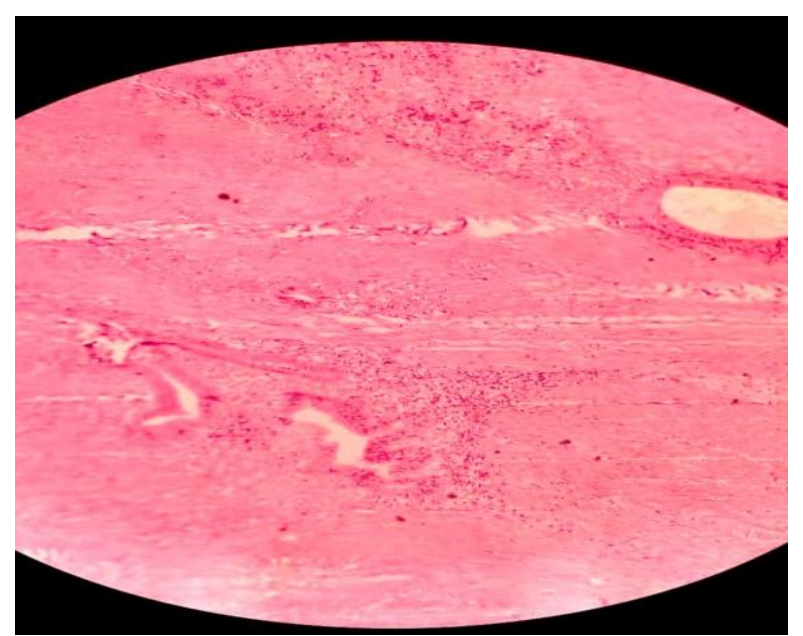

Fig-3: Section studied shows fibrofatty and fibro collagenous tissue with many Endometrial glands and stromal elements along with skeletal muscle tissue and neural tissue [H \&E,x40]

\section{DISCUSSION}

Endometriosis was first described by Karl Von Rokitansky in 1860. It is a chronic gynecologic disorder where the functional and morphological endometrial glands and stroma are present outside the uterine cavity [5]. It mainly affects women in reproductive ages. Major sites for extrapelvic endometriosis include the lungs, pleura, kidneys, bladder, omentum, bowel, lymph nodes, and abdominal wall.

Abdominal wall endometriosis is one of the most frequent extra pelvic locations, mostly occurring in old surgical scars from obstetrical and gynecological procedures

According to Nominato et al., cesarean section remains the most common surgical procedure related to the development of abdominal wall scar endometriosis [6]. They published an estimated incidence of 0.2 to $0.45 \%$ though it remains difficult to evaluate as most of the literature available is based on case reports and small series. More recently, in a study examining a cohort of 151 patients diagnosed with cesarean section scar endometriosis (CSE), Zhang and Liu reported an incidence of $1.96 \%$ [7].

The pathogenesis of endometriosis is complex and CSE is believed to be the result of a mechanical iatrogenic implantation, through the direct inoculation of the abdominal fascia and/or subcutaneous tissue with endometrial cells during the surgical intervention, which, stimulated by estrogen, become active and expand [8]. Wang et al., examined the factors contributing to CSE and defined possible causes, including the easy separation and transport of endometrial cells by the amniotic fluid flowing into the pelvic cavity after hysterotomy; the large amount of endometrial cells liberated into the pelvis before hysterotomy closure and that can potentially be trapped in the wound; and the nurturing role of blood and hormones, after inoculation of the cells, allowing them to grow and develop into subcutaneous masses. It is important to highlight that higher incidence is reported after early hysterotomy (end of second or beginning of third trimester), as early decidua seems to have more pluripotential capabilities and can result in enhanced cellular replication producing endometriosis. This was supported by our case, as the patient developed CSE after a cesarean at 32 weeks.

The lesions in the differential diagnosis of mass associated with abdominal scar have well-defined cytological features. Desmoid tumor and fibrosis show less cellularity with benign-appearing mesenchymal cells. Suture granuloma shows non-specific inflammation with or without granulomatous elements and foreign material. Fat necrosis shows foamy macrophages, inflammatory and multinucleated giant cells, fragments of adipose tissue and no epithelial cells. Nodular fasciitis shows myxoid background and 
pleomorphic cells. Smears from primary or metastatic malignancies show hypercellularity with frankly neoplastic cells.

Scar endometriosis is a rare condition that affects women of reproductive age because of typical clinical history and clear-cut cytomorphological features. Cytodiagnosis of scar endometriosis was rendered without any difficulty in this patient. Thus, FNAC is an inexpensive, rapid and reliable method to conclude the diagnosis before surgery.

Although it is fairly diagnosed on an adequate biopsy specimen, based on the presence of any two of the three histological components, including endometrial glands, stroma and macrophages, a challenge occurs of diagnosing endometriosis on a fine needle aspiration cytology (FNAC) that at times, becomes the first diagnostic modality in such cases, especially when the available clinical details are limited and some of the cytological features are atypical. Cutaneous endometriosis is a recognized diagnostic pitfall on cytological smears.

Scar endometriosis is relatively rare entity and usually associated with cesarean section scar.

Fine needle aspiration cytology is economical, fast and accurate method to make the diagnosis of scar endometriosis and to plan better surgical approach. More cases of scars endometriosis studies by FNAC are necessary to confirm the usefulness of this diagnostic tool. Surgical removal is the treatment of choice.

\section{REFERENCES}

1. Catalina-Fernández I, López-Presa D, SáenzSantamaria J. Fine needle aspiration cytology in cutaneous and subcutaneous endometriosis. Acta Cytol. 2007; 51:380-384.

2. Agarwal A, Fond YF. Cutaneous endometriosis. Singapore Med J. 2008; 49:704-9.

3. Pathan SK, Kapila K, Haji BE, Mallik MK, AlAnsary TA, George SS, Das DK, Francis IM. Cytomorphological spectrum in scar endometriosis: a study of eight cases. Cytopathology. 2005 Apr;16(2):94-9.

4. Medeiros FD, Cavalcante DI, Medeiros MA, Eleutério J, Jr. Fine needle aspiration cytology of scar endometriosis: Study of seven cases and literature review. Diagn Cytopathol. 2011; 39:1821.

5. American College of Obstetricians and Gynecologists, "Practice bulletin no. 114: management of endometriosis, Obstetrics \& Gynecology, 2010; 116(1):223-236.

6. Nominato NS, Prates LF, Lauar I, Morais J, Maia L, Geber S. Caesarean section greatly increases risk of scar endometriosis. European Journal of Obstetrics \& Gynecology and Reproductive Biology. 2010 Sep 1;152(1):83-5.

7. Zhang J, Liu X. Clinicopathological features of endometriosis in abdominal wall-clinical analysis of 151 cases. Clin Exp Obstet Gynecol. 2016 Jan 1;43(3):379-83.

8. Sasson IE, Taylor HS. Stem cells and the pathogenesis of endometriosis. Annals of the New York Academy of Sciences. 2008 Apr;1127:106115 . 